\title{
The role of apatinib combined with paclitaxel (aluminum binding type) in platinum-resistant ovarian cancer
}

Hong Zhao ${ }^{1 *} \mathbb{D}$, Rong $\mathrm{Li}^{1}$, Xiaoyan Wang ${ }^{2}$, Xin $\mathrm{Lu}^{1}$, Min $\mathrm{Hu}^{1}$, Jinbin Zhang ${ }^{2}$, Xia Zhao ${ }^{3}, X_{i}$ Yangyang Liu $^{4}$

\section{Abstract}

Objective: To assess the anti-tumor activity and side effects of different dosages of pac $x e l$ (albumin binding type) (hereinafter referred to as nab-P) combined with Apatinib (hereinafter rete to as AP) in platinum-resistant ovarian cancer cell line and xenograft models.

Methods: SKOV-3/DDP cell line was selected as the research object in cytolog, vperiment. Firstly, we divided it into three groups for experiments to explore the individual effects of and AP. a): Control group, blank control, no drug intervention; b): nab-P group, nab-P $40 \mu \mathrm{mol} / /$; $\mathrm{C}$ ): AP group, A $80 \mathrm{pm}$ mol/I (Drug doses were IC-50 values that detected by MTT assay). Apoptosis related protein (Bax, $\mathrm{hcl}-2$ ), vascular related protein(p-VEGFR-2), invasion related protein (MMP-2) expression were detected by Wern a and Cellular immunofluorescence, the invasion ability of tumor cells were detected by Transwell and Celi atch est. Based on these dates, secondly, establishing different doses of nab-P combined with Ap to explore the cu tife effect of combination therapy. a): Control group, blank control, no drug intervention; b): Group-1, 1, P untol/1 + AP $10 \mu \mathrm{mol} / \mathrm{I}, \mathrm{c})$ : Group-2, nab-P $4.5 \mu \mathrm{mol} / \mathrm{I}+\mathrm{AP}$ $10 \mu \mathrm{mol} / \mathrm{l}, \mathrm{d})$ : Group-3, nab-P $4 \mu \mathrm{mol} / \mathrm{I}+\mathrm{AP} 10 / \mathrm{mol} / \mathrm{n}$, nab-P group, nab-P $5 \mu \mathrm{mol} / \mathrm{l}$, f): AP group, AP $10 \mu \mathrm{mol} / \mathrm{I}$ (MTT assay). The combination index was anan, do by mpusyn software, Western blot, Immunofluescence, Transwell and Cell scratch test also were also ch, v to observe of inhibition effect. Thirdly, we used xenograft models to verify the results of cytolo gical experiments. Tumor-forming BALB/C female nude mice were randomly divided into 4 groups, a): Control gr Ip, no oljug intervention, only saline injection, b): nab-P 20 mg/kg + AP 150 $\mathrm{mg} / \mathrm{kg}, \mathrm{c}):$ nab-P $18 \mathrm{mg} / \mathrm{kg}+$ AP $150 \quad$ d $):$ nab-P $16 \mathrm{mg} / \mathrm{kg}+$ AP $150 \mathrm{mg} / \mathrm{kg}$ (The doses were guided by the pharmaceutical manufacturers, tumor growth curve was analyzed during the experiment. And the apoptosis related protein (Bax, bcl-2), ang logern, sis related protein (CD31, p-VEGFR-2) and invasion related protein (MMP-2) were observed by Weste blot, Immunofluescence and Immunohistochemistry to analysis the ant-tumor effects. The quality of life in de $\mathrm{de}$ were observed to analysed the drug-induced side effects.

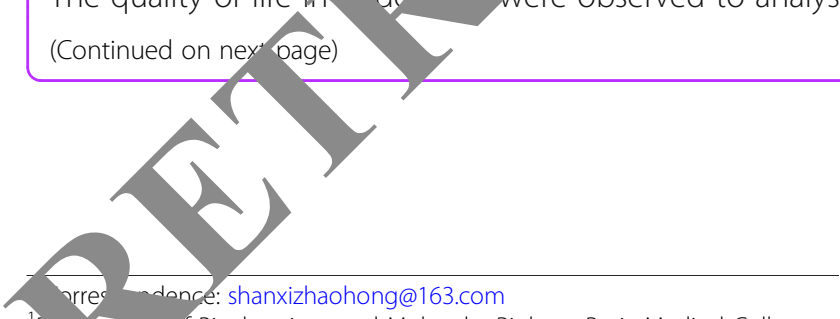

'D. tment of Biochemistry and Molecular Biology, Basic Medical College,

Shan adical University, No. 56 Xinjian South Road, Yingze District, Taiyuan City, Sh, nxi Province, China

Full list of author information is available at the end of the article

\section{$\triangle B M C$}

(c) The Author(s). 2020 Open Access This article is licensed under a Creative Commons Attribution 4.0 International License, which permits use, sharing, adaptation, distribution and reproduction in any medium or format, as long as you give appropriate credit to the original author(s) and the source, provide a link to the Creative Commons licence, and indicate if changes were made. The images or other third party material in this article are included in the article's Creative Commons licence, unless indicated otherwise in a credit line to the material. If material is not included in the article's Creative Commons licence and your intended use is not permitted by statutory regulation or exceeds the permitted use, you will need to obtain permission directly from the copyright holder. To view a copy of this licence, visit http://creativecommons.org/licenses/by/4.0/ The Creative Commons Public Domain Dedication waiver (http://creativecommons.org/publicdomain/zero/1.0/) applies to the data made available in this article, unless otherwise stated in a credit line to the data. 
(Continued from previous page)

Result: In the separate medication section, (1) The IC-50 value of nab-P was $45.53 \pm 4.06 \mu$ mol/I, while the AP was $50.66 \pm 4.96 \mathrm{umol} / \mathrm{L}$ (48 h). (2) The expressions of bcl-2 (nab-P group, AP group), p-VEGFR-2 (AP group), MMP-2(nabP group, AP group) were higher than Control group, while Bax (nab-P group, AP group) lower $(P<0.01)$. (3) The cell invasive ability was decreased after the nab-P and AP intervation $(P<0.01)$. In the combination medication section, (1) Compusyn showed the Combination index $(\mathrm{Cl})$ were all below $1(\mathrm{Cl}<1)$, that means nab-P and AP are synergism. (2) The combination IC-50 value was nab-P $5.28 \mu \mathrm{mol} / \mathrm{I}+\mathrm{AP} 10.56 \mu \mathrm{mol} / \mathrm{I}$ (48 h). (3) In the detect. related protein expression, the combination of drugs can improve the anti-tumor effect, otherwise, after comb with $A P$, when nab-P were reduced dose in proper quantity, there were no obvious different in drug /ffect. (4) After reducing the doses of nab- $P$, the average food intake of nude mice increased from $4.50 \mathrm{~g} \pm \mathrm{Q} 1 \mathrm{~T} .55 \mathrm{~g}$ 0.13, and the one-hour activity increased from $6.11 \mathrm{~min} \pm 0.16$ to $6.34 \mathrm{~min} \pm 0.13$.

Conclusion: nab-P, a chemotherapeutic agent, can play an anti-tumor role in platinum-resista ovarian cancer, but it can cause adverse effects that increase with dose. When combined with AP, the two d rs h, cyr,ergistic effect, which can improve the anti-tumor effects of single drug. In addition, when cop inine vith AP, the doses of nab-P can be appropriately reduced under the standard of recommended to reduc he toxicy, of chemotherapy drugs, without affecting the anti-tumor effect.

Keywords: Apatinib, Paclitaxel (aluminum binding type), Ovarian cancer, Combr medication

\section{Introduction}

Ovarian cancer (hereinafter referred to as OC) is one of the three common malignant tumors of female genital system, known as "silent killer". Because OC is a high malignancy with insidious onset, invasive fast-growing, high recurrence rate and fatality, most patients have reached the late stage (stage III or IV) when th. medical advice. According to the 2018 lates of 1 statistics released by the international car researc, center, the number of morbidity and deaths fro. $Q C$ in the world is 295,000 and 185,000 , res ectively [1].) $n$ the 2019 version, the National Comprel nsive Cancer Network (NCCN) guides the first-line c otb rapies that are still represented by platin These drugs have a significant effect on the treatnen patients, with a five-year survival rate on $7 \%$ [.], but about $60 \%$ will recurrence unfortun $\mathrm{l}_{\mathrm{y}}$, In addition, among these patients, most of titse platinum-resistant recurrence (platinum-free $\mathrm{val}<6 \mathrm{l}$, onths). Platinum-resistant recurrent is an imp ant factor that makes the patient's condition difficult to control. There are studies have shown that mo t.an $0 \%$ of patients with platinum-resistant rec ont only 12-18 months for progression-free rrviv (PFS) [4]. More importantly, the number of $\mathrm{pa}$ nts wo develop platinum-resistance are increasing, $\operatorname{com}_{\mathrm{P}}$ ed with $30-40 \%$ of OC patients with platinumresistance in 2012 [5], the data in 2019 increased to 70$80 \%$ [6]. In response to the above phenomena, in clinic, most platinum-free drugs are chosen to improve the sensitivity of the patient itself, such as liposome adriamycin, nab-P and so on [7].

nab-P is based on paclitaxel, and human albumin is added as carrier and stabilizer, and the molecular weight is about $130 \mathrm{~nm}$. It can be directionally adsorbed on the correspon tumor cells by SPARC protein, and then kill them [31/Cympared with standard paclitaxel, it can increase the local cancentration of drugs, enhance the anc mor effect, and improve its own stability and afety In 2005, a phase III clinical trial of breast cancer w d that nab-P was significantly more effective than standard paclitaxel (effective rates were 33 and 17\%, respectively, $P=0.001$ ) [9]. In other study of xenograft models of lung, ovarian, prostate and colon cancer, nab$\mathrm{P}$ produced less drug toxicity than standard paclitaxel at the same dose [10]. In addition, nab-P also played a good synergistic effect in combination therapy, such as Volk's research in breast cancer, combined with bevacizumab had gotten satisfactory results [11].

In recent years, the development of targeted antitumor drugs has promoted the precise treatment process of cancer. Tyrosine kinase (TK) is an important target only next to $G$ protein-coupled receptor [12], and one study has shown that tyrosine kinase inhibitors (TKI) can increase the effect of chemotherapy drugs, mainly by inhibiting the function of ABC transporter [13]. Apatinib, a TKI-targeted drug, can highly selectively act on the ATP binding site of vascular endothelial growth factor receptor-2 (VEGFR-2), and then block the downstream phosphorylation of VEGFR-2 to inhibit tumor angiogenesis [14]. Many research have shown that AP has showed strong tumor inhibition and individual tolerance in non-small cell lung cancer, gastric cancer, breast cancer and other malignant solid tumors [15-17]. In OC, many achievements have also been made. In a phase II clinical study of recurrent epithelial ovarian cancer, the objective response rate (ORR) of patients was $41.4 \%$, and PFS was 14.5 months [18]. In 2018, an article published in Lancet Oncol on the treatment of advanced 
ovarian cancer patients with AP and Etoposide showed that up to $54 \%$ of patients achieved remission [19], and in the same year, Jiuhuan [20] found that the combination of AP and standard paclitaxel can significantly inhibit tumor growth.

Therefore, we propose whether AP combined with nab-P can improve the therapeutic effect on OC patients. Moreover, because the recommended dosage of nab-P is $260 \mathrm{mg} / \mathrm{m}^{2}$, the use of large dosage aggravates the physiological burden of patients inevitably, we assumed that if we can reduce the dosage of nab-P without effecting the efficacy after combination with AP. This paper preliminarily discusses the antitumor effect of the combination of nab-P and AP in the treatment of $\mathrm{OC}$, so as to provide reference for clinical medicine.

\section{Materials and methods}

\section{Equipments and drugs}

The equipments used in the experiment is as follows: Power Pac-TM Alkaline electrophoresis apparatus (1645051, Bio-Rad), Gel imaging analysis system (SYNGENE G: BOXChemiXR5), Microplate Reader (Awareness Stat Fax, USA).

The drugs used in the experiment are as follows: Apatinib tablets (Jiangsu Hengrui Pharmaceutical Co., Ltd., Jiangsu, China, H20140103, $250 \mathrm{mg}$ ), paclitaxel (aluminum bin ang type) (Shiyao Holding Group Co., Ltd., Shijiazhuang, 'in H20183318, 100 mg). Use after dissolving witb Dime r Sulfoxide (DMSO, Sigma-Aldrich Co., St Louio, 'O, USA,

\section{Cell lines and culture}

SKOV-3/DDP cell line was purchase from Procell (Procell Life Science \& Technology Co., L. Wulan, China), and identified by short tandem at (STR) analysis. The cell line was cultured in RPMI 154 , dium (Boster Biological Technology co,.I a Wuhan, China), supplemented with $10 \%$ fetal bovi- ser (Cellmax, Beijing, China), and incubated in $2{ }^{\circ} \mathrm{C}, \mathrm{CO} \mathrm{CO}_{2}$ incubator.

\section{Cytotoxicity assay}

The cyto oxicities of $2, \mathrm{P}$ and nab-P for SKOV-3/DDP cell line wer $16 . . \mathrm{rm}$ ned by MTT assay (Sigma-Aldrich Co., St is, $M_{4}$ U/ A). Inoculate $1 \times 10^{4}$ cells/well in 96 well Il $\mathrm{Cl}$ true claster. The concentration range of nab-P were 5. $5 \times 10^{2} \mu \mathrm{mol} / \mathrm{l}$, and AP $10^{-1}$ to $10^{3} \mu \mathrm{mol} / \mathrm{l}$. In the 6 erimental group, $100 \mu \mathrm{l}$ drug was added into each pore, while control group replaced serum-free medium. Add $20 \mu \mathrm{l}$ MTT to each hole, and then $150 \mu \mathrm{l}$ DMSO after $4 \mathrm{~h}$ at $37^{\circ} \mathrm{C}$, shake for $30 \mathrm{~min}$. Measure the optical density $(\mathrm{OD})$ at $490 \mathrm{~nm}$ with enzyme standard meter.

\section{Combination index}

On the basis of the IC-50 values of SKOV-3/DDP by nab-P and AP, the data map of $\mathrm{Fa}-\mathrm{Cl}$ plot established by compusyn (version 2.0) software was used to analyze the combination of drugs. Synergism $(\mathrm{Cl}<1)$ : greater than expected additive effect. Additive effect $(\mathrm{Cl}=1)$ : the combined effect predicted by the mass-action law principle in the absence of synergism or antagonism. Antagonism $(\mathrm{Cl}>1)$ : small than expected additive ffect.

\section{Western blot assay}

Total cellular protein was extracted y h RIPA lyate buffer (Boster Biological Technology) ont. ing $\mathrm{p}$ otease inhibitor and phosphorylase inhil for (Bosto siological Technology), and determined pro in concentration with BCA protein detection kit (B ter ogic A Technology), then separated by SDS-PA GE trophoresis kit (cwbiotech). The amount of e group $\mathrm{p}$ teins was $20 \mu \mathrm{g}$. After separation, the proeins ere transferred to PVDF membrane $(0.22 y$ When áled by $0.5 \%$ non-fat milk powder still 11 the VDF membrane was incubated with polyclonal prim anubody and secondary antibody combineo with HRi 1 he membrane was colored by ECL enhanced tho minescence kit (Boster Biological Technology) and formed by Biological Spectrum Image System ning.

Pr ary antibodies used in this study include anti- $\beta$ tin (:5000, AP0060, Bioworld Technology, Inc), at -bcl-2(1:1000, AF6139, Affinity), anti-Bax(1:1000, 1F0120, Affinity), anti-p-VEGFR-2(1:500, AF3279, Affinity), anti-MMP-2(1:500, AF5330, Affinity). The secondary antibodies include HRP-conjugated affinipure goat anti-Rabbit IgG(1:5000, Boster Biological Technology, BA1054).

\section{Immunofluorescence}

SKOV-3/DDP different groups were inoculated in 6 well cell cultrue cluster. A slide was placed in each hole for cell climbing. The inoculation amount of each hole was controlled at $10^{5}$ cells. After the cells adhered to the wall, PBS was soaked for $3 \mathrm{~min} \times 2$ times. Cells were fixed with $4 \%$ paraformaldehyde and soaked with PBS. Cells were permeable with $0.5 \%$ Triton X-100 room temperature. PBS was rinsed again. The PBS was dried by absorbent paper, and then the normal goat serum blocking solution was dripped on the slide for $30 \mathrm{~min}$. The absorbent paper was dried. Each slide was dripped with a sufficient amount of diluted first antibody, and put into a wet box. After incubation at $4{ }^{\circ} \mathrm{C}$ overnight, it was soaked by PBST. After absorbing the superfluous liquid, the absorbent paper dripped with $\mathrm{CY} 3$ labeled Goat anti rabbit IgG, incubated in a wet box at $37^{\circ} \mathrm{C}$ for $1 \mathrm{~h}$, and then washed with PBS. DAPI was dripped in the dark and incubated in dark for $5 \mathrm{~min}$. In the dark place, absorbent paper is used to absorb the climbing liquid, and the sealing liquid containing anti fluorescence quenching agent (Boster Biological Technology) was 
used for sealing. Images were collected under fluorescence microscope. Follow the same steps for frozen section.

Primary antibodies used in this study include anti-bcl2(1:200, AF6139, Affinity), anti-Bax(1:200, AF0120, Affinity), anti-p-VEGFR-2(1:200, AF3279, Affinity), anti-CD31(1: 200, BS90231, Bioworld Technology), The secondary antibodies include $\mathrm{CY} 3$ conjugated affinipure goat anti-rabbit IgG(1:200, Boster Biological Technology, BA1032).

\section{Transwell invasion assay}

The SKOV-3/DDP cell line was treated in RPMI 1640 medium with serum free for $24 \mathrm{~h}$. Then $1 \times 10^{5}$ cells in $100 \mu \mathrm{l}$ medium were respectively sucked into upper chamber of transwell $(8 \mu \mathrm{m}$ pore size) with $20 \mu \mathrm{l}$ pre-coated Matrigel (coring), $500 \mu \mathrm{l}$ culture medium containing 20\% FBS was added into the lower chamber to stimulate cell travelling. After $24 \mathrm{~h}$ culture at $37^{\circ} \mathrm{C}, 5 \% \mathrm{CO}_{2}$ incubator, transwell chambers were fixed using $4 \%$ paraformaldehyde, and then stained with $0.1 \%$ crystal violet. Cells laid on upper surface of transwell membrane were wiped using a cotton swab, while cells traveled to the lower surface of membrane were photographed under a microscope. The average transmitted cells were counted in five random fields.

\section{Wound healing assay}

$5 \times 10^{5}$ cells were inoculated into 6 well cell cultr $2 \mathrm{lu}$ ter and maintained in incubator for $12 \mathrm{~h}-24 \mathrm{~h}$ antil " $\mathrm{s}$ reached $100 \%$ confluence. Then the cell mo. Jyer wa scratched to create a gap with $100 \mu \mathrm{l}$ pipette tip "lowed by PBS washing. Finally, the culture nedium was changed into serum free RPMI 1640 med $\mathrm{m}$. The gaps were observed and photo- graphed at $0 \mathrm{~h}$, h an $24 \mathrm{~h}$ after scratching, the area of scrat were calculated by Image J software.

\section{Xenograft model}

The BALB/C-nu were rrchased from Charles River Laboratories $C_{A}$ all of nese were almost 5-week-old female nude mous This study was accomplish with the approval of the ethigal committee of Provincial Cancer Hospita, Chani, China, and followed the institutional guiline a e ethical standard. In order to establish subtan bus tyansplanted OC model, $2 \times 10^{6}$ SKOV-3/ D. Cerrine was injected into the right axilla of each mou When the axillary tumor volume of the nude mice was $200 \mathrm{~mm} 3$, the nude mice were randomly divided into four groups, six in each group, and the following interventions were carried out every day. a): Control group, no drug intervention, ntraperitoneal perfusion of $200 \mu \mathrm{l} \mathrm{NS}, \mathrm{b}$ ): Group-1, nab-P $20 \mathrm{mg} / \mathrm{kg}$, intraperitoneal perfusion+AP $150 \mathrm{mg} / \mathrm{kg}$, gavage administration, c): Group-2, nab-P 18 $\mathrm{mg} / \mathrm{kg}$, intraperitoneal perfusion+AP $150 \mathrm{mg} / \mathrm{kg}$, gavage administration, d): Group-3, nab-P $16 \mathrm{mg} / \mathrm{kg}$, intraperitoneal
perfusion+AP $150 \mathrm{mg} / \mathrm{kg}$, gavage administration. Record the diet and exercise status, and measure the tumor size axis every other day,

The xenografts were measured by caliper, and the tumor volume was calculated based on length $(\mathrm{L})$ and the width (W) by the following formula: $\mathrm{V}=1 / 2 \times \mathrm{L} \times \mathrm{W}^{2}$.

\section{Immunohistochemistry}

The tissue was dehydrated by sucrose, then each. ae made a frozen-section, $16 \mu \mathrm{m}$, lined witu thesive shdes. Incubated with $3 \%$ hydrogen peroxia at room temperature for $10 \mathrm{~min}$, washed oy PBS for $2 \mathrm{~min} \times 3$ times; normal goat serum wa incubated at room temperature for $10 \mathrm{~min}$, the sean vith appropriate proportion of diluted pr mary a body, washed by PBS for $2 \mathrm{~min} \times 3$ times $\mathrm{c}$ ent at $4 \mathrm{C}$, drip with ready to use secondary antibody, in bated at $37^{\circ} \mathrm{C}$ for $30 \mathrm{~min}$, washed by PBS 10r $\min \times 3$ times, drip with fresh $\mathrm{DAB}$ Color developh control the color developing time under the $\mathrm{m}$. ascope, wash completely with water, re-dye by hemaxoxylin solution for several seconds, wash with wate, dry the color developing tablets after alcohol, seal them with neutral gum, and observe under the icroscope.

\section{ticical analysis}

SPsS 21.0 software was used to analyze the data (Means \pm SD). Paired samples were analyzed by paired sample T-test, and multiple samples were analyzed by one-way analysis of variance; $P<0.05$ was statistically significant.

\section{Result}

Effect of nab-P and AP on SKOV-3/DDP

Before exploring the combination therapy, we examined the inhibitory effect of nab-P and AP alone on ovarian cancer cells. In order to simulate platinum-resistant OC patients, we selected platinum-resistant SKOV-3 cell line that can highly express VEGFR-2, that is SKOV-3/DDP.

First, we determined the drugs concentrations of nab$\mathrm{P}$ and nab-P by half inhibition concentration (IC-50) values obtained from MTT assay. Nine concentration gradients $\left(5 \times 10^{-2}\right.$ to $5 \times 10^{2}$ of nab-P, $10^{-1}$ to $10^{3}$ of AP) were established to intervene for 24,48 , and $72 \mathrm{~h}$ respectively. The results (Fig. 1a) showed that the drugs effect on SKOV-3/DDP were obviously concentration and time dependent manner. The IC-50 values were showed in Table 1. Divided SKOV-3/DDP into 3 groups and treated with nab-P and AP according to their $48 \mathrm{~h}$ IC-50 values. a): Control group, no drug intervention to set the black control, b): nab-P group, nab-P $20 \mu \mathrm{mol} / \mathrm{l}$, c): AP group, AP $50 \mu \mathrm{mol} / \mathrm{l}$.

The Bax and bcl-2 are the most commonly used proteins to detect apoptosis, SKOV-3 is ovarian cancer cell 


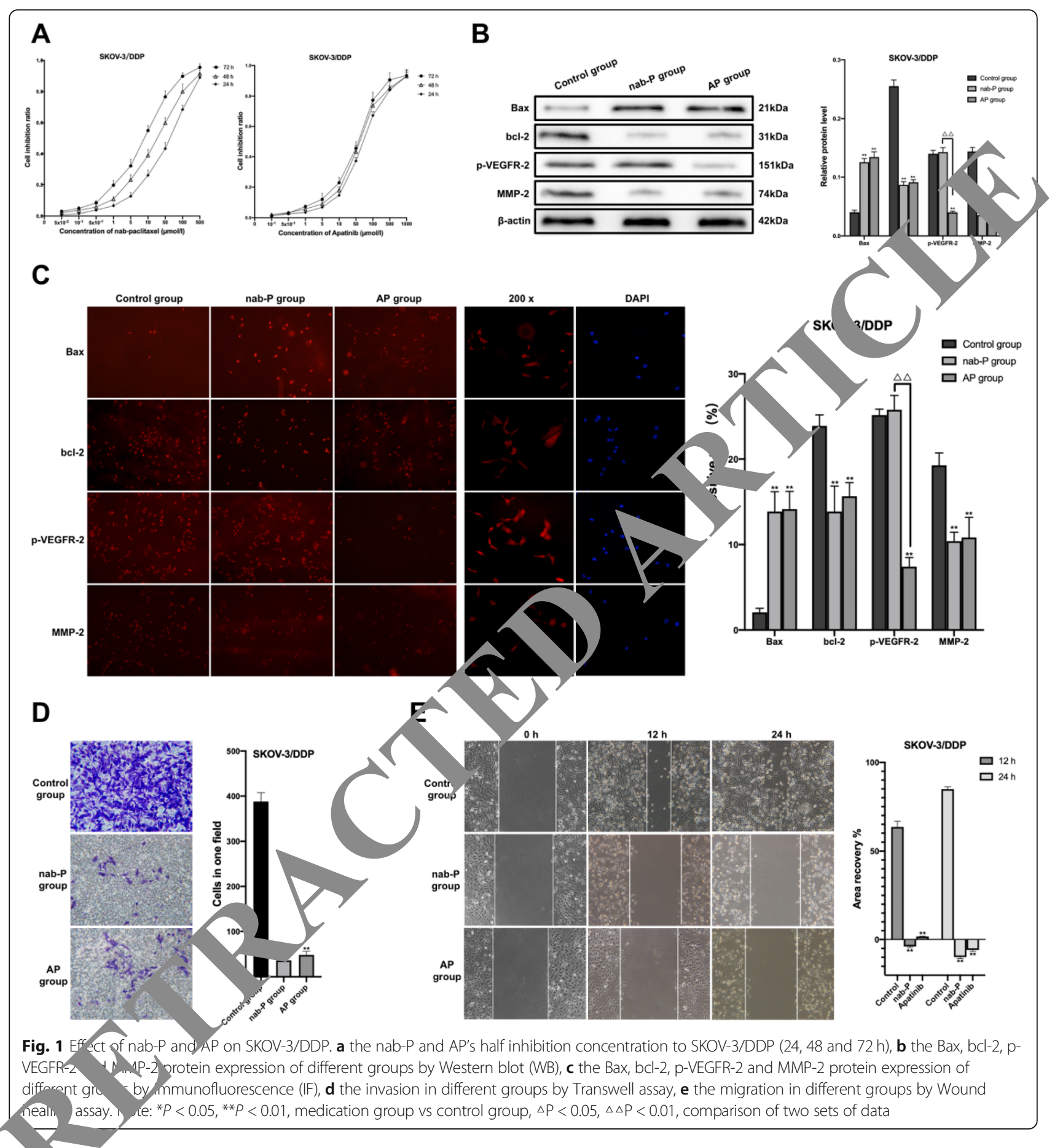

line with high expression of VEGFR-2, and AP can inhibit tumor angiogenesis by inhibiting the formation of p-VEGFR-2, and MMP-2 is closely related to the ability

Table 1 IC-50 value of nab-P and AP on SKOV-3/DDP ( $\bar{x} \pm$ SD)

\begin{tabular}{llll}
\hline & & nab-P group & AP group \\
\hline $\mathrm{IC}-50(\mu \mathrm{mol} / \mathrm{l})$ & $24 \mathrm{~h}$ & $45.53 \pm 4.06$ & $65.74 \pm 8.33$ \\
& $48 \mathrm{~h}$ & $20.88 \pm 2.99$ & $50.66 \pm 4.96$ \\
& $72 \mathrm{~h}$ & $8.77 \pm 0.64$ & $39.54 \pm 6.62$ \\
\hline
\end{tabular}
of invasion of tumor cell. So we used Western blot (WB) and Immunofluorescence (IF) to detect the expression of Bax, bcl-2, p-VEGFR-2 and MMP-2, and Image J software was used to analyze (Fig. 1b, c). The results were showed in Table 2. The difference between Control group and medication groups were all statistically significant $(P<$ 
Table 2 The results of WB, IF, Transwell and Would healing assay ( $\bar{x} \pm$ SD)

\begin{tabular}{|c|c|c|c|c|}
\hline & & Control group & nab-P group & AP group \\
\hline \multirow[t]{4}{*}{ WB (relative gray value) } & Bax & $0.04 \pm 0.01$ & $0.13 \pm 0.07$ & $0.14 \pm 0.09$ \\
\hline & bcl-2 & $0.26 \pm 0.01$ & $0.09 \pm 0.01$ & $0.09 \pm 0.01$ \\
\hline & p-VEGFR-2 & $0.14 \pm 0.04$ & $0.14 \pm 0.06$ & $0.04 \pm 0$. \\
\hline & MMP-2 & $0.14 \pm 0.01$ & $0.04 \pm 0.01$ & \\
\hline \multirow[t]{4}{*}{ IF (positive rate\%) } & Bax & $2.01 \% \pm 0.39$ & $13.87 \% \pm 1.91^{* *}$ & \\
\hline & bcl-2 & $23.9 \% \pm 1.04$ & $13.87 \% \pm 2.45^{* *}$ & \\
\hline & p-VEGFR-2 & $25.17 \% \pm 0.97$ & $25.8 \% \pm 1.94$ & \\
\hline & MMP-2 & $19.3 \% \pm 1.16$ & $10.4 \% \pm 0.85^{* *}$ & $92^{* *}$ \\
\hline Transwell (invasion cellular amount) & & $389 \pm 25.8$ & $41 \pm 7.6^{* *}$ & $53 \pm 4.7^{* *}$ \\
\hline \multirow[t]{2}{*}{ Wound healing (Area recovery\%) } & $12 \mathrm{~h}$ & $63.54 \% \pm 3.64$ & $-3.89 \%$ & $-9.85 \% \pm 0.62^{* *}$ \\
\hline & $24 \mathrm{~h}$ & $84.88 \% \pm 1.75$ & 1.76 & $-5.87 \% \pm 0.62^{* *}$ \\
\hline
\end{tabular}

0.01). Meanwhile, the inhibition effect of nab-P and AP on the invasion of SKOV-3/DDP were verified by Transwell and Cell scratch tests (Fig. 1d, e). The results also showed in Table 2. Compared with Control group, the difference were statistically significant $(P<0.01)$.

\section{Effects of different doses of nab-P combined with AP on SKOV-3/DDP}

From what is said above, we can draw a conclusi th for SKOV-3/DDP, both nab-P and AP can exentsatis tory anti-tumor effects alone. However, the nncentra tion of drugs is relatively high, so we envision hether the combination of two drugs can $r$ duce the doses of drugs and achieve the anti-tumor ef ct of $1+1>2$. We designed the following experiments. We wed a fixed concentration ratio of nab-P: $1: 2$ to act on SKOV3/DDP.

MTT assay detectin he IC -50 value was nab-P

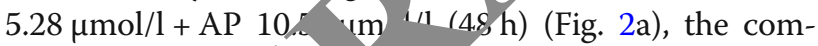
bined inhibition index T) was all belowed 1(Fig. 2b), that men nab/ ombine, with AP on SKOV-3/DDP had synergistic et In clinic, side effects caused by chemoth rapeutic ag nts are often positively correlated with ar dosagt Therefore, we proposed whether the do of na. could be appropriately reduced after the गmb ration of AP without affecting the anti-tumor $\mathrm{e}_{\mathrm{L}}$. $w$ designed the following groups, a): Control grou $_{1}$ ho drug intervention to set the black group; b): Group-1, nab-P $5 \mu \mathrm{mol} / 1+\mathrm{AP} 10 \mu \mathrm{mol} / \mathrm{l} ; \mathrm{c})$ : Group-2, nab-P $4.5 \mu \mathrm{mol} / \mathrm{l}+\mathrm{AP} 10 \mu \mathrm{mol} / \mathrm{l} ; \mathrm{d})$ : Group-3, nab-P $4 \mu \mathrm{mol} / \mathrm{l}+\mathrm{AP} 10 \mu \mathrm{mol} / \mathrm{l}$, in which the drug dose of Group-1 was formulated according to the MTT, and the drug concentration of nab-P in Group-2 and Group-3 decreased with $0.5 \mu \mathrm{mol} / \mathrm{l}$ in turn. At the same time, designing e): nab-P group: nab-P $5 \mu \mathrm{mol} / \mathrm{l}$ and $\mathrm{f}$ ): AP $10 \mu \mathrm{mol} / \mathrm{l}$ as the drug control group for comparison.
The expressio $\mathrm{f}-2$, p-VEGFR-2 and MMP-2 in SKOV-3/DDP wer. 'so detected by WB and IF (Fig. 2c, d). The inhib offect of nab-P combining with AP on the invasion were alyo verified by Transwell and Cell scratch tests (Fig. 2 . f). Compared with the Control group, the dim nce was obviously significant $(P<0.01)$. And there till $\mathrm{u}$ re no significant difference between the three medi- groups. In addition, there were significant differences in apoptosis, invasion and angiogenesis between nab-P and AP alone group and Group-1.

The results showed that reducing dose of nab-P had no significant effect on the anti-tumor activity when combined with AP, the results were showed as Table 3.

\section{Effects of different doses of nab-P combined with AP on xenograft models}

Through the above two parts of the experiment, we can get that nab-P combined with AP can significantly inhibit tumor growth and promote apoptosis of SKOV-3/ DDP. When the dosage of nab-P is properly reduced, it can still achieve satisfactory anti-tumor effect. Therefore, at the cellular level, nab-P can reduce the dosage when combined with AP. We go further to design in vivo experiments to verify whether the results are consistent with those of in vitro.

After the establishment of xenograft models, the tumor volumes were recorded every other day (Fig. 3a), and the results as showed in Table 4. We found that there was no significant difference in tumor volume between the three medication groups, but there was between Control group $(P<0.01)$.

We also analyzed the expression of related proteins in tumor masses by WB, IF and immunohistochemistry (IHC) (Fig. 3c, d, e). The three medication groups were had no difference between them, while compare with Control group, there were all significant $\operatorname{difference}(P<$ 


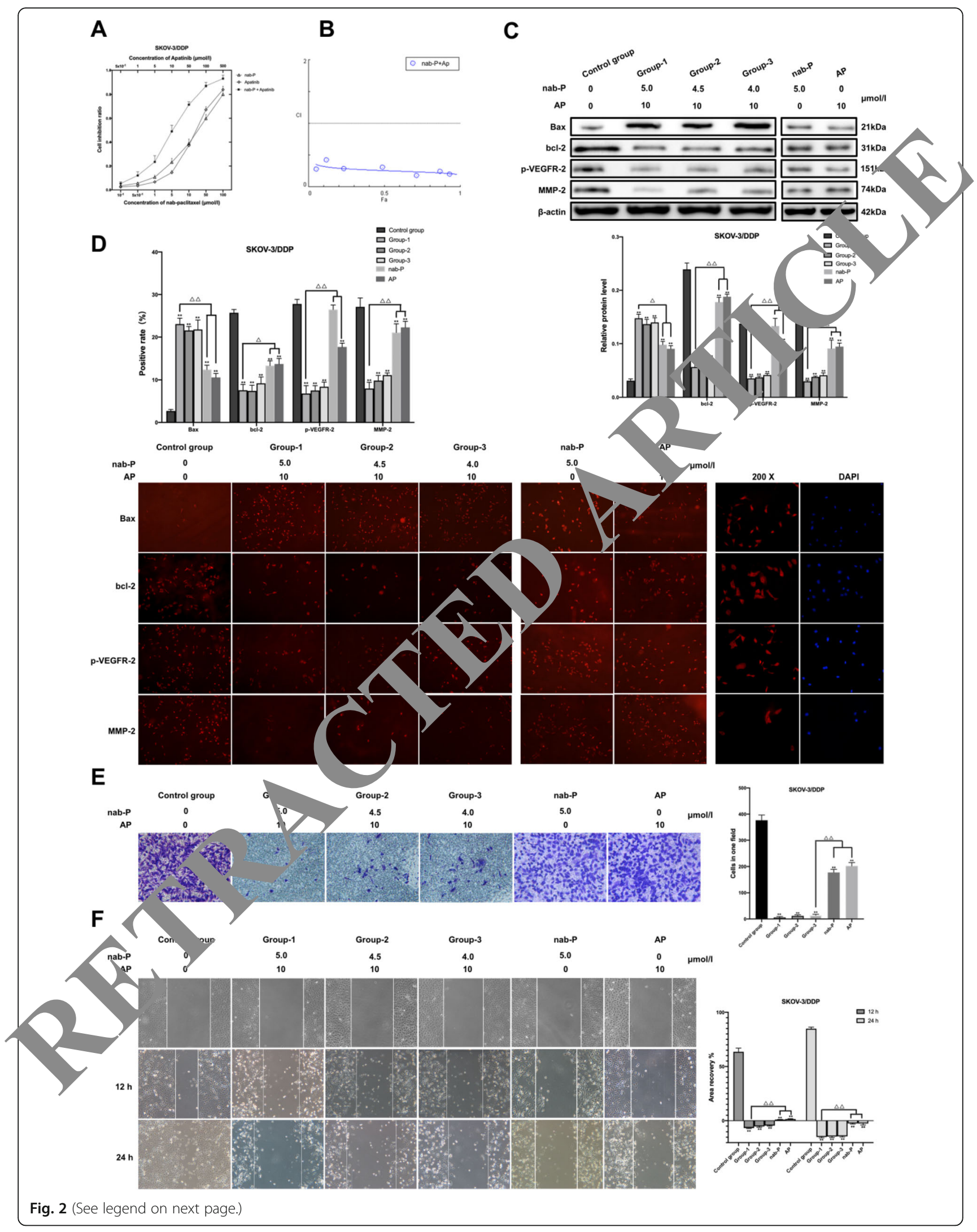


(See figure on previous page.)

Fig. 2 Effects of different doses of nab-P combined with AP on SKOV-3/DDP. a the nab-P combined with AP's half inhibition concentration to SKOV-3/DDP (24, 48 and $72 \mathrm{~h}$ ), b Combined inhibition index, $\mathbf{c}$ the Bax, bcl-2, p-VEGFR-2 and MMP-2 protein expression of different groups by Western blot (WB), $\mathbf{d}$ the Bax, bcl-2, p-VEGFR-2 and MMP-2 protein expression of different groups by Immunofluorescence (IF), e the invasion in different groups by Transwell assay, $\mathbf{f}$ the migration in different groups by Wound healing assay. Note: ${ }^{*} P<0.05$, ${ }^{*} P<0.01$, medication group vs control group, $\Delta P<0.05, \Delta \Delta P<0.01$, comparison of two sets of data

0.01). The WB's relative gray value and IF, IHC 's positive rate(\%) as Table 5.

During the experiment, by observing the quality of life of the mice, we found that after the intervention of nab$\mathrm{P}$ and AP, the majority side effects in the medication groups were anorexia and decreased activity. Therefore, we evaluated the quality of life of different groups by average amount of daily diet and $1 \mathrm{~h}$ activity (Table 6). There is no apparent difference of the quality of life in the 4 groups before the treatment. When AP combined with different doses of nab-P, the quality of life was negatively correlated with the dose of nab-P. The difference of two evaluation indexes between the each experimental groups and the control group were statistically significant $(\mathrm{P}<0.01)$.

\section{Discussion}

Although the therapeutic technologies for ovarian cancer continues to improve, the mortality rate remains /igh [21], especially for patients with recurrent ep oli 1 ovarian cancer. More importantly, the long-tent us f chemotherapeutics will damage the norma issues of patients, result in drug resistance in patients, on the failure of clinical treatment [22]. In t'is experime, 1 , we tested the targeting drug AP in coml nation with several different doses chemotherapeutics na aga hst SKOV3/DDP. And results showed th play satisfactory anti-tumor elfecos gainst platinumresistant ovarian cance s, anc when combined, their respective anti-tumor effects are enhanced. Furt. nore. when combined with AP, if nab-P properly reduce two drugs can still achieve ideal anti-tum effect.

The following will elaborate.

Firstly, we analyzed the drug e ects of nab-P and AP alone at the cellular level. Wo ob ined the IC-50 value of nab-P and AP to SKOV- DP. results showed that IC-50 of nab-P wo lower an AP, this indicated that the drug effect $o r$ o on S,OV-3/DDP is slightly stronger. Apoptosis is a fò of cell death, which plays an important ore maintaining the balance between normal cell de ell division [23]. Inhibition of apoptosis and abr $\mathrm{mal}$ cell proliferation and differenti-

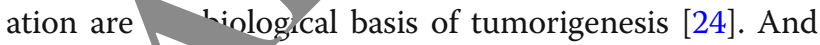
promoting apop-osis of tumor cells is one of the most important methods in tumor therapy [25]. The proteins or and bcl-2 are key in regulating apoptosis. Therecore, e used WB and IF to analyze the effect of treated t the expression of these two proteins. The results showed after nab-P and AP intervention, the expression of Bax was higher than Control group, bcl-2 contrary. That's means that both nab-P and AP can promote apoptosis of SKOV-3/DDP. Tumor growth mainly depends on tumor angiogenesis [26], and vascular endothelial growth factor (VEGF) is an important factor in the latter. Distributing widely in normal and tumor tissues, it can stimulate the proliferation, survival and migration of endothelial cells through the corresponding cell surface receptors and signal pathways, which is one

Table 3 The result of WB, Transwell and Would healing assay $(\bar{x} \pm S D)$

\begin{tabular}{|c|c|c|c|c|c|c|c|}
\hline & & Control group & Group-1 & Group-2 & Group-3 & nab-P & AP \\
\hline & & $0.03 \pm 0.00$ & $0.15 \pm 0.01^{* *}$ & $0.14 \pm 0.01^{* *}$ & $0.14 \pm 0.01^{* *}$ & $0.10 \pm 0.02^{* *}$ & $0.09 \pm 0.00^{* *}$ \\
\hline & & $0.24 \pm 0.01$ & $0.06 \pm 0.01^{* *}$ & $0.06 \pm 0.01^{* *}$ & $0.06 \pm 0.01^{* *}$ & $0.18 \pm 0.01^{* *}$ & $0.19 \pm 0.02^{* *}$ \\
\hline & p-VEGFR-2 & $0.14 \pm 0.01$ & $0.03 \pm 0.00^{* *}$ & $0.04 \pm 0.00^{* *}$ & $0.04 \pm 0.00^{* *}$ & $0.13 \pm 0.01$ & $0.09 \pm 0.00^{* *}$ \\
\hline & MMP-2 & $0.16 \pm 0.01$ & $0.03 \pm 0.00^{* *}$ & $0.04 \pm 0.00^{* *}$ & $0.04 \pm 0.00^{* *}$ & $0.09 \pm 0.01^{* *}$ & $0.09 \pm 0.00^{* *}$ \\
\hline & Bax & $2.7 \% \pm 0.29$ & $23.07 \% \pm 1.13^{* *}$ & $21.57 \% \pm 0.67^{* *}$ & $21.8 \% \pm 1.8^{* *}$ & $12.4 \% \pm 1.07^{* *}$ & $10.57 \% \pm 0.68^{* *}$ \\
\hline & bcl-2 & $25.7 \% \pm 0.65$ & $7.57 \% \pm 1.11^{* *}$ & $7.4 \% \pm 1.1^{* *}$ & $8.2 \% \pm 1.2^{* *}$ & $13.33 \% \pm 1.96^{* *}$ & $13.73 \% \pm 0.71^{* *}$ \\
\hline & $p-V E G F R-2$ & $27.8 \% \pm 0.86$ & $6.8 \% \pm 1.51^{* *}$ & $7.5 \% \pm 0.94^{* *}$ & $8.4 \% \pm 0.88^{* *}$ & $24.47 \% \pm 2.27$ & $17.7 \% \pm 0.52^{* *}$ \\
\hline & MMP-2 & $27.1 \% \pm 1.7$ & $7.97 \% \pm 1.2^{* *}$ & $9.83 \% \pm 1.01^{* *}$ & $11.13 \% \pm 0.4^{* *}$ & $21.07 \% \pm 1.14^{* *}$ & $22.27 \% \pm 0.97^{* *}$ \\
\hline $\begin{array}{l}\text { Transwell (invasion } \\
\text { cellular amount) }\end{array}$ & & $391 \pm 21.7$ & $6 \pm 1.3^{* *}$ & $12 \pm 2.6^{* *}$ & $14 \pm 1.9^{* *}$ & $197 \pm 29.9^{* *}$ & $216 \pm 26.1^{* *}$ \\
\hline \multirow{2}{*}{$\begin{array}{l}\text { Wound healing } \\
\text { (Area recovery\%) }\end{array}$} & $12 \mathrm{~h}$ & $63.54 \pm 4.48$ & $-6.56 \pm 0.39^{* *}$ & $-5.28 \pm 0.53^{* *}$ & $-4.5 \pm 0.39^{* *}$ & $1.03 \pm 0.05^{* *}$ & $-2.46 \pm 0.27^{* *}$ \\
\hline & $24 \mathrm{~h}$ & $84.88 \pm 2.15$ & $-14.8 \pm 0.7^{* *}$ & $-14.37 \pm 0.73^{* *}$ & $-14.15 \pm 0.61^{* *}$ & $1.51 \pm 0.07^{* *}$ & $-2.51 \pm 1.18^{* *}$ \\
\hline
\end{tabular}

Note: ${ }^{* *} P<0.01$, medication group vs control group 


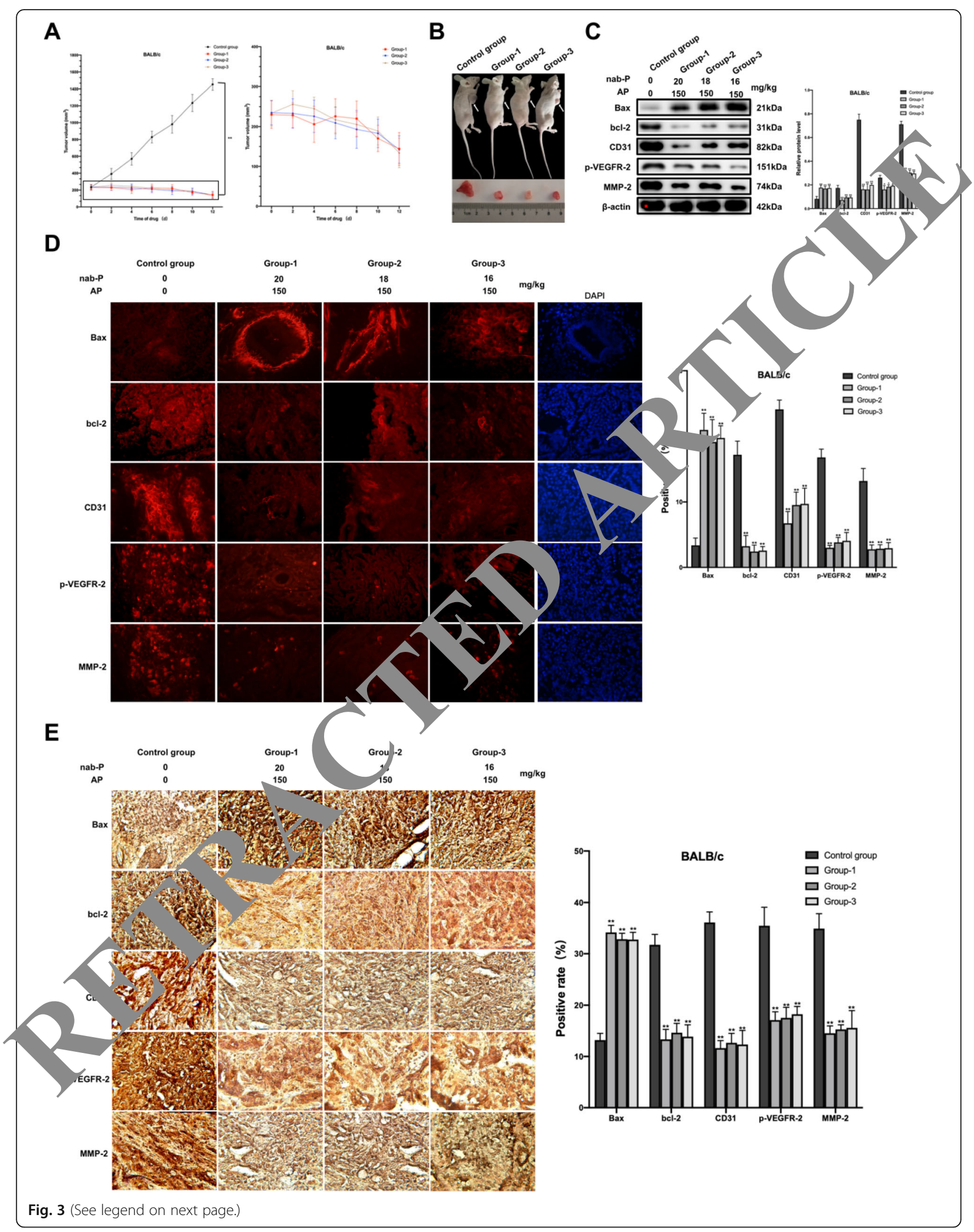


(See figure on previous page.)

Fig. 3 Effects of different doses of nab-P combined with AP on BALB/C. a Growth curve of subcutaneous tumor in four groups of mice, $0 \mathrm{~d}$ repressed the first day of drug intervention, $\mathbf{b}$ mice and volume of tumor after exfoliation, $\mathbf{c}$ the Bax, bcl-2, CD31, p-VEGFR-2 and MMP-2 protein expression of different groups by Western blot, $\mathbf{d}$ the Bax, bcl-2, CD31, p-VEGFR-2 and MMP-2 protein expression of different groups by Immunofluorescence (400x), e the Bax, bcl-2, CD31, p-VEGFR-2 and MMP-2 protein expression of different groups by Immunohistochemistry (400x). Note: ${ }^{*} P<0.05,{ }^{* *} P<0.01$, medication group vs control group, $\Delta P<0.05, \Delta \Delta P<0.01$, comparison of two sets of data

of the important factors for the growth and survival of endothelial cells [27]. VEGFR is the main functional receptor of VEGF, and its subtype, VEGFR-2, is considered to be a key molecule in the VEGF signaling pathway that induces angiogenesis. So, inhibiting the binding of VEGF R-2 to VEGF or the transmission of its downstream signaling pathways all can achieve the purpose of inhibiting tumor angiogenesis and then tumor growth [28]. Targeting drug Apatinib can specifically act at the ATP binding site of VEGFR-2, inhibiting the production of p-VEGFR2 and blocking downstream signal transduction pathways. Therefore, we tested expression of p-VEGFR-2 in different groups. The results also confirmed that in AP group, the expression of p-VEGFR-2 was reduction, while there was no significant difference between nab-P group and control group. Several studies have shown that matrix metalloproteinases play an important role in tumor cell invasion and metastasis [29], while MMP 2 is an important component [30]. In medication grok th o expression of MMP-2 were declined when compa $d$ with Control group. We also used Transy and $\mathrm{Ce}_{\text {, }}$ scratch test to verify the changes of invarion an nigration of SKOV-3/DDP in different gro ps. As the sy,me as the expected results, after the interv tion of nab-P and AP, the invasive ability of cells in vit and healing rate decreased significantly. Thereft we can draw the first conclusion that nab-P and AI C ray a good antitumor effect on SKOV or PP. The results are the same with Jing, Momeny, $Z$ tor an [31-33]

However, consiacring the limitation of single drug therapy, comb in the apy is a routine means for clinical tumor trea ent [34]. In recent years, the combination of chemoth-rapeutics and targeted drugs has made' $s_{c}$ if cant breakthroughs in both basic research and linica nplication of OC $[19,35,36]$. nab-P is a

Table, Changes of tumor volume before and after administration in different groups $(\bar{x} \pm S D)$

\begin{tabular}{lll}
\hline Tumor volumes $\left(\mathrm{mm}^{3}\right)$ & Drug-before & Drug-after \\
\hline Control group & $234.83 \pm 28$ & $1452.83 \pm 61.47$ \\
Group-1 & $230.17 \pm 31.66$ & $144 \pm 37.65^{* *}$ \\
Group-2 & $224.83 \pm 28$ & $142.33 \pm 31.4^{* *}$ \\
Group-3 & $233.67 \pm 29.37$ & $138.83 \pm 31.43^{* *}$ \\
\hline
\end{tabular}

Note: ** $P<0.01$, medication group vs control group kind of paclitaxel wrapped by human albumin, can enter the tumor cells easily, increas he dru concentration in tumor cells, and achieveidea he apeutic effect on OC. Nevertheless, onc the tumor burden is reduced after nab-P treatment, it ay lead to increased reactivity of VEGF signaling thwa, spression [37]. If some inhibitor about VFGF is us at the same time, the expression of VEGF na relates proteins will be continuously inhibited. tumor rigogenesis will be reduced simultaneously so a to achieve better anti-tumor effect, AP is such on pect the combination of these two drugs to be $\mathrm{m}$ effective.

Accordi above-mentioned analytical results, we designed the se, ond part of the experiment. We also tested the inhibitory effect of nab-P combined AP on SK -3/DDP by MTT assay, and with the help of comusyr (version 2.0) software analysised the $\mathrm{Cl}$ of the two oc. The results showed that, after nab-P combined win AP, it had a strong inhibitory effect on SKOV-3/ DDP, and played a synergistic effect. On the basis of IC50 value, we set up the different concentration of nab-P combined with AP as combination groups, and the same dose of nab-P and AP single drug as drug control groups to explore the improvement effect of anti-tumor and the influence of different doses of nab-P on the efficacy. Western blot and immunofluorescence experiments also be used to observe the expression of related proteins (Bax, bcl-2, p-VEGFR-2 and MMP-2). According to the results, after combined with AP, appropriate reduction of nab-P did not affect the anti-tumor effect of both drugs, while compared with nab-P and AP single drug group, the difference were statistically significant. Transwell and Cell scratch test's results also showed the combination of drugs greatly weakened the invasion and migration of SKOV-3/DDP. Above that, we can obtain another conclusion that at the cellular level, when nab-P and AP are used in combination, the idea of reducing drug toxicity by reducing the amount of nab-P is feasible.

After obtaining satisfactory results at the cell level, we designed animal experiments to verify whether the results of the combination drugs at the animal level are consistent with those at the cell. This is also the third part of the experiment. Different concentration of nab-P were combined with the same dose of AP. The shrinkage of tumor mass were observed by calculating the volume of subcutaneous tumor in mice after administration. The 
Table 5 The results of WB, IF, IHC ( $\bar{x} \pm S D)$

\begin{tabular}{|c|c|c|c|c|c|}
\hline & & Control group & Group-1 & Group-2 & Group-3 \\
\hline \multirow[t]{5}{*}{ WB (relative gray value) } & Bax & $0.08 \pm 0.02$ & $0.18 \pm 0.12^{* *}$ & $0.17 \pm 0.17^{* *}$ & $0.17 \pm 0.02^{* *}$ \\
\hline & bcl-2 & $0.17 \pm 0.02$ & $0.07 \pm 0.01^{* *}$ & $0.09 \pm 0.01^{* *}$ & $0.09 \pm 0.01^{* *}$ \\
\hline & CD31 & $0.75 \pm 0.04$ & $0.16 \pm 0.02^{* *}$ & $0.16 \pm 0.04^{* *}$ & $0.2 \pm 0.01^{* *}$ \\
\hline & p-VEGFR-2 & $0.26 \pm 0.02$ & $0.16 \pm 0.03^{* *}$ & $0.18 \pm 0.01^{* *}$ & \\
\hline & MMP-2 & $0.71 \pm 0.02$ & $0.29 \pm 0.03^{* *}$ & $0.3 \pm 0.02^{* *}$ & \\
\hline \multirow[t]{5}{*}{ IF (positive rate\%) } & Bax & $3.37 \% \pm 0.91$ & $20.97 \pm 2.09^{* *}$ & $19.13 \pm 2.78^{* *}$ & \\
\hline & bcl-2 & $17.17 \pm 1.69$ & $3.23 \pm 1.35^{* *}$ & $2.43 \pm 0.79^{* *}$ & \\
\hline & CD31 & $24.1 \pm 1.15$ & $6.73 \pm 1.47^{* *}$ & 9.53 & \\
\hline & p-VEGFR-2 & $16.77 \pm 1.03$ & $3.0 \pm 0.29^{* *}$ & & $\pm 1.04^{* *}$ \\
\hline & MMP-2 & $13.2 \pm 1.53$ & $2.77 \pm 0.54^{* *}$ & & $2.93 \pm 0.69^{* *}$ \\
\hline \multirow[t]{5}{*}{ IHC (positive rate\%) } & Bax & $13.2 \% \pm 1.07$ & $34.17 \pm 1.11^{* *}$ & & $32.77 \pm 1.16^{* *}$ \\
\hline & bcl-2 & $31.73 \pm 1.67$ & $13.33 \pm 1.59^{* *}$ & & $13.87 \pm 1.89^{* *}$ \\
\hline & CD31 & $36.1 \pm 1.69$ & $11.63 \pm 1.2^{* *}$ & & $12.33 \pm 2.24^{* *}$ \\
\hline & $\mathrm{p}-\mathrm{VEGFR-2}$ & $35.47 \pm 2.93$ & $17.1 \pm 1.31^{*}$ & $\pm 1.6^{* *} 8$ & $18.23 \pm 1.25^{* *}$ \\
\hline & MMP-2 & $34.9 \pm 2.38$ & $14.53 \pm 1.17^{*}$ & $15.27 \pm 0.74^{* *}$ & $15.57 \pm 2.75^{* *}$ \\
\hline
\end{tabular}

Note: ${ }^{*} P<0.01$, medication group vs control group

results showed that after the combination treatment, the tumor volume decreased significantly, and there was no significant difference among the three combinzan groups. In addition, Western blot, immunofluore no and immunohistochemistry were carried out $0 \mathrm{de}$ de the related proteins. The results showed tha expres sion of bcl-2, CD31, p-VEGFR-2, MMP 2 all a reased significantly while Bax increased, c mpared wi, 1 the control group, the difference was sta stically kignificant, but there were no obvious differenc mong the three combination groups, which w highly consistent with the experimental results at the dell $/ y$, The side effects caused by chemother Po trugs are important factors affecting the quality life natients [38]. In order to verify the effect red " $g$ the doses of nab-P on the survival of nua nice, $w_{y}$ set up two observation indexes: average an nt of daily diet and one hour exercise. We found $t$, at there was a significant negative correlat Dutwen the quality of life of mice and the do of b. P. Therefore, we can draw the third
COn sion, that is, in vivo experiments, after nab-P omb led with AP, appropriate reduction of the recomnded dosage of nab-P can achieve the purpose of reaucing the adverse reactions in mice.

In a word, in this experiment, we combined the targeting drug AP with the chemotherapy drug nab-P to act on the SKOV-3/DDP and xenograft models, and found that the combination of the two drugs can significantly inhibit the proliferation and invasion of the tumor. Secondly, after the combination, it can be properly reduced the doses of nab-P without effecting the anti-tumor effects. This suggests that, in the clinical treatment, the scheme of combination can bring less side effects.

Due to the certain toxicity of chemotherapy drugs, patients are prone to some adverse reactions such as myelosuppression, gastrointestinal reactions, etc. Therefore, if the combination can reduce the dosage of nab- $\mathrm{P}$ on the basis of not reducing the therapeutic effect, and the adverse reactions will be correspondingly reduced, which may improve the quality of life of patients.

Tak 6 Effects of different doses of nab-P combined with AP on the quality of life of mice

\begin{tabular}{|c|c|c|c|c|c|c|c|}
\hline \multirow[t]{2}{*}{ Group } & \multirow{2}{*}{$\begin{array}{l}\text { Total } \\
\text { (n) }\end{array}$} & \multicolumn{3}{|c|}{ Average amount of daily diet(g) } & \multicolumn{3}{|c|}{ One hour activity (min) } \\
\hline & & Before medication & After medication & $\mathbf{P}$ & Before medication & After medication & $\mathbf{P}$ \\
\hline Control group & 6 & $6.79 \pm 0.21$ & $6.90 \pm 0.19$ & 0.64 & $18.63 \pm 0.15$ & $19.35 \pm 0.14$ & 0.62 \\
\hline Group-1 & 6 & $6.78 \pm 0.21$ & $4.50 \pm 0.17^{* *}$ & $<0.01$ & $17.54 \pm 0.15$ & $6.11 \pm 0.16^{* *}$ & $<0.01$ \\
\hline Group-2 & 6 & $6.91 \pm 0.19$ & $5.64 \pm 0.15^{* *}$ & $<0.01$ & $17.68 \pm 0.15$ & $6.29 \pm 0.12^{* *}$ & $<0.01$ \\
\hline Group-3 & 6 & $6.62 \pm 0.16$ & $5.55 \pm 0.13^{* *}$ & $<0.01$ & $17.95 \pm 0.14$ & $6.34 \pm 0.13^{* *}$ & $<0.01$ \\
\hline
\end{tabular}

Note: Average daily intake represents the average food consumption of mice in the two stages (Before and After medication, Control group was replaced by NS), One hour activity expresses activity time of mice within one hour from 9:00 to 10:00 and 21:00 to 22:00, ${ }^{* *} P<0.01$, medication group vs control group 


\section{Abbreviations}

OC: Ovarian cancer; NCCN: The National Comprehensive Cancer Network; PFS: Progression-free survival; nab-P: Paclitaxel (aluminum binding type); AP: Apatinib; TK: Tyrosine kinase; TKl: Tyrosine kinase inhibitors; VEGFR2: Vascular endothelial growth factor receptor-2; ORR: Objective response rate; VEGF: Vascular endothelial growth facto; Cl: Combination index

\section{Acknowledgements}

Thanks to the biochemistry and Molecular Biology Department of Shanxi Medical University for providing some necessary instruments and equipment, and thanks to the gynecologist of Shanxi cancer hospital for providing clinical guidance.

\section{Authors' contributions}

Hong Zhao*: Put forward the whole idea of experiment design and important experiment's design. Jinbin Zhang: Provide guidance for animal experiment operation. Min Hu: Be responsible for experiment record. Rong Li: Assist Hong Zhao to design and implement the major experiment. Xiaoyan Wang: Be responsible for correcting errors in the process of experiment and providing technical guidance. Xin Lu: Be responsible for part of the operation of cytology experiment and the breeding of nude mice. Xia Zhao: Provide theoretical help for the preparation of the experiment. Xiaogin Song: Be responsible for conventional culture of cells. Yangyang Liu: Be responsible for configuration of some reagents. All authors read and approved the final manuscript.

\section{Funding}

This study was funded by Natural science gene of Shanxi Province (Xiaoyan Wang grant number 2013011045-4).

\section{Availability of data and materials}

The datasets used and analysed during the current study are available from the corresponding author (Rong Li) on reasonable request.

Ethics approval and consent to participate Not applicable.

Consent for publication Not applicable.

Competing interests

The authors declare that they have no competing terests.

Author details
${ }^{1}$ Department of Biochemistry and Moleculor Basic Medical College, Shanxi Medical University, No. 56 Xinjian So th/Roa , Yingze District, Taiyuan City, Shanxi Province, China. ${ }^{2} \mathrm{D}$ ent of iynecology, Shanxi Cancer Hospital, Taiyuan, China. ${ }^{3}$ Sh 2 ij pro nce cen 4 f for disease control and prevention, Taiyuan, Chine ${ }^{4}$ Th mated Hospital of Shanxi Medical University, Taiyuan, Chi ra.

Received: 16 Apri, 2020 repted: 14 September 2020

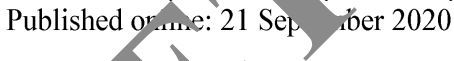

Reference.

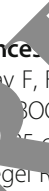

1. Rray F, Fe V., So - ijomataram I, et al. Global cancer statistics 2018 :

G. BOCAN mates of incidence and mortality worldwide for 36 cancers

in Onuntiles. CA Cancer J Clin. 2018. https://doi.org/10.3322/caac.21492.

2. eger n, willer K, Jemal A. Cancer statistics, 2018. CA Cancer J Clin. 2018. ydoi.org/10.3322/caac.21442.

3. Sh, DH, Kwon GS. Pre-clinical evaluation of a themosensitive gel containing epothilone B and $\mathrm{m}$ TOR/Hsp90 targeted agents in an ovarian tumor model. J Control Release. 2017. https://doi.org/10.1016/j.jconrel.2017. 10.022.

4. Papa A, Caruso D, Strudel M, et al. Update on poly-ADP-ribose polymerase inhibition for ovarian cancer treatment. J Transl Med. 2016. https://doi.org/ 10.1186/s12967-016-1027-1.

5. Joseph PC, Mildred F, Arvinder K, et al. DcR3 binds to ovarian cancer via heparan sulfate proteoglycans and modulates tumor cells response to platinum with corresponding alteration in the expression of BRCA1. BMC Cancer. 2012. https://doi.org/10.1186/1471-2407-12-176.
6. Meshach AW, Kiran N, Arkadiy R, et al. The exosome-mediated autocrine and paracrine actions of plasma gelsolin in ovarian cancer chemoresistance. Oncogene. 2019. https://doi.org/10.1038/s41388-019-1087-9.

7. Stukova M, Hall MD, Tsotsoros SD, et al. Reduced accumulation of platinum drugs is not observed in drug--resistant ovarian cancer cell lines derived from cisplatin-treated patients. J Inorg Biochem. 2015. https://doi.org/10 1016/j.jinorgbio.2015.05.003.

8. Du X, Khan AR, Fu M, et al. Current development in the formulation of non-injection administration ofpaclitaxel. Int J Pharm. 2018. 10.1016/j.jpharm.2018.03.030.

9. Gradishar WJ, Phase III. Trial of nanoparticle albumin-bound paclita compared with Polyethylated Castor oil-based paclita 4 in women breast Cancer. J Clin Oncol. 2005. https://doi.org/10.12 'CO.2005 4.937.

10. Desai N, Trieu V, Yao Z, et al. Increased antitumon ctivity, ratun/or paclitaxel concentrations, and endothelial c transport of cophor-free, albumin-bound paclitaxel, ABI-007, compar with crempphor-based paclitaxel. Clin Cancer Res. 2006. http///do/ 10.1200/CO.2005.04.937.

11. Volk LD, Flister MJ, Chihade D, et ar. rgy o uclitaxel and bevacizumab in eradicating larg ovtho breast tumors and preexisting metastases. Neoplasia. 2011 "Ds://doi.org, /593/neo.101490.

12. Naruse I, Ohmori T, Ao Y et al. itumor aetivity of the selective epidermal growth factor receptor-tyrosine $k_{m} \quad$ iphibitor (EGFR-TKI) Iressa ${ }^{\oplus}$ (ZD1839) in an EGFR-expresn Itidrug-res, ant cell line in vitro and in vivo. Int J Cancer. 2002. b. r.//dd bra/10.1002/ijc.10173.

13. Csilla H, Tamás Resistance to Target nticancer Kinase Inhibitors. Anticancer Kinase Inhibitol cistance to argeted ABC Transporters in Cancer. 2015. https:// doi.org/1 low 2/319-09801-2_9.

14. Haijun Z. A patinib/or molecular targeted therapy in tumor. Drug Des Devel Ther. 2015. Ittms://doi.org/10.2147/DDDT.S97235.

rtin R, Ror $K$, Anders M, et al. Docetaxel plus Nintedanib versus docetaxel placebo in patients with previously treated non-small- cell lung cancer (LC IE-lung 1): a phase 3, double-blind, randomised controlled trial. Lancet rcol. 2014. https://doi.org/10.1016/S1470-2045(13)70586-2.

16. Hu X, Cao J, Hu W, et al. Multicenter phase II study of apatinib in non-triplenegative metastatic breast cancer. BMC Cancer. 2014. https://doi.org/10. 1186/1471-2407-14-820.

17. Liao Z, Li F, Zhang C, et al. Phase II trial of VEGFR2 inhibitor apatinib for metastatic sarcoma: focus on efficacy and safety. Exp Mol Med. 2014. https://doi.org/10.1038/s12276-019-0221-7.

18. Miao M, Deng G, Luo S, et al. A phase II study of apatinib in patients with recurrent epithelial ovarian cancer. Gynecol Oncol. 2018. https://doi.org/10. 1016/j.ygyno.2017.12.013

19. Lan $C$, Wang $Y$, Xiong $Y$, et al. Apatinib combined with oral etoposide in patients with platinum-resistant or platinum-refractory ovarian cancer (AEROC): a phase 2, single-arm, prospective study. Lancet Oncol. 2018. https://doi.org/10.1016/S1470-2045(18)30349-8.

20. Jiuhuan F, Shukui Q. The synergistic effects of Apatinib combined with cytotoxic chemotherapeutic agents on gastric cancer cells and in a fluorescence imaging gastric cancer xenograft model. Onco Targets Ther. 2018. https://doi.org/10.2147/OTT.S159935.

21. Yao S, Xiao W, Chen H, et al. The combined detection of ovarian Cancer biomarkers HE4 and CA125 by a fluorescence and quantum dot dual-signal immunoassay. Anal Methods. 2019. https://doi.org/10.1039/C9AY01454C.

22. Feng $Y$, Huang $H$, Wan $T$, et al. Comparison of PARPis with angiogenesis inhibitors and chemotherapy for maintenance in ovarian Cancer: a network meta-analysis. Adv Ther. 2019. https://doi.org/10.1007/s12325-019-01106-1.

23. Liu J, Liu X, Ma W, et al. Anticancer activity of cucurbitacin-A in ovarian cancer cell line SKOV3 involves cell cycle arrest, apoptosis and inhibition of mTOR/ PI3K/Akt signaling pathway. J Buon. 2018;23(4):124-8. PMID: 29552771.

24. Chen $X B, K o L$, Jayaraman $L$, et al. P53 levels, functional domains, and DNA damage determine the extent of the apoptotic response of tumor cells. Genes Dev. 1996. https://doi.org/10.1101/gad.10.19.2438.

25. Melet A, Song K, Bucur O, et al. Apoptotic pathways in tumor progression and therapy. Adv Exp Med Biol. 2008. https://doi.org/10.1007/978-1-4020-6554-5_4.

26. Pang $\mathrm{P}$, Wang $\mathrm{Y}$. Asymptotic behavior of solutions to a tumor angiogenesis model with chemotaxis-haptotaxis. Math Models Methods Appl Sci. 2019. https://doi.org/10.1142/S0218202519500246.

27. Shibuya M. Vascular endothelial growth factor (VEGF) and its re captor (VEGFR) signaling in angiogenesis: a crucial target for anti-and pm-Angiogenic therapies. Genes Cancer. 2011. https://doi.org/10.1177/1947601911423031. 
28. Hong P, Qiu YZ, Jiali L, et al. Apatinib inhibits VEGF signaling and promotes apoptosis in intrahepatic cholangio carcinoma. Oncotarget. 2016. https:// doi.org/10.18632/oncotarget.7948..

29. Beroun A, Mitra S, Michaluk P, et al. MMPs in learning and memory and neuropsychiatric disorders. Cell Mol Life Sci. 2019. https://doi.org/10.1007/ s00018-019-03180-8.

30. Coniglio SJ, Segall JE. Review: molecular mechanism of microglia stimulated glioblastoma invasion. Matrix Biol. 2013. https://doi.org/10.1016/j.matbio. 2013.07.008.

31. Jing $D$, Xiao-Yan, et al. Apatinib exerts anti-tumour effects on ovarian cancer cells. Gynecol Oncol. 2019;2019. https://doi.org/10.1016/j.ygyno.2019.01.010.

32. Momeny M, Sabourinejad Z, Zarrinrad G, et al. Anti-tumour activity of tivozanib, a pan-inhibitor of VEGF receptors, in therapy-resistant ovarian carcinoma cells. Sci Rep. 2017. https://doi.org/10.1038/srep45954.

33. Tipton AR, Nabuto GO, Trendel JA, et al. Guanylate-binding Protein-1 protects ovarian cancer cell lines but not breast cancer cell lines from killing by paclitaxel. Biochem Biophys Res Commun. 2016. https://doi.org/10.1016/ j.bbrc.2016.08.169.

34. Lv H, Ma X, Yu W, et al. Effect of combined medication of exemestane and docetaxel on the growth of human endometrial carcinoma xenograft in nude mice. J Clin Oncol. 2011. https://doi.org/10.3969/j.issn. 1000-8179.2011.09.001

35. Wu YS, Shui L, Shen D, et al. Bevacizumab combined with chemotherapy for ovarian cancer: an updated systematic review and meta-analysis of randomized controlled trials. Oncotarget. 2017. https://doi.org/10.18632/ oncotarget.12926.

36. Rivkin SE, Iriarte $\mathrm{D}$, Sloan $\mathrm{H}$, et al. Phase Ib/Il with expansion of patients at the MTD study of olaparib plus weekly (metronomic) carboplatin and paclitaxel in relapsed ovarian cancer patients. Clin Cancer Res. 2014. https:// doi.org/10.1158/1557-3265.OVCASYMP14-AS28.

37. Volk LD, Flister MJ, Bivens CM, et al. Nab-paclitaxel efficacy in the orthotopic model of human breast cancer is significantly enhanced by concurrent antivascular endothelial growth factor a therapy. Cancer Res. 2008. https://doi. org/10.1593/neo.08302.

38. Zhao S, Cao W, Xing S, et al. Enhancing effects of Theanine liposom soN chemotherapeutic agent on tumor therapy. ACS Biomater Sci Eng. https://doi.org/10.1021/acsbiomaterials.9b00317.

\section{Publisher's Note}

Springer Nature remains neutral with regard to juris ictional claims published maps and institutional affiliations.

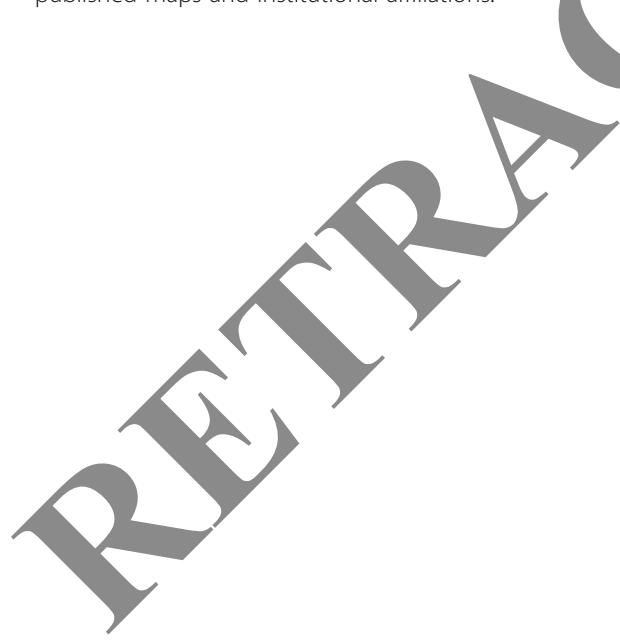

Ready to submit your research? Choose BMC and benefit from:

- fast, convenient online submission

- thorough peer review by experienced researchers in your field

- rapid publication on acceptance

- support for research data, including large and complex data types

- gold Open Access which fosters wider collaboration and increased citations

- maximum visibility for your research: over $100 \mathrm{M}$ website views per year

At $\mathrm{BMC}$, research is always in progress.

Learn more biomedcentral.com/submissions 